\title{
If it ain't broke, don't fix it (much)
}

Modest structural reforms could help the US National Institutes of Health to maintain its independence - and the public's confidence.

$\square$ mployees at the National Institutes of Health (NIH) in Bethesda, Maryland, have been chafing lately under what many regard as unwarranted micromanagement by officials at the Department of Health and Human Services. And some members of Congress are casting an unusually critical eye over the agency: in June, one committee began investigating awards given to Richard Klausner in 1999, when he directed the National Cancer Institute. It broadened its investigation after press reports that an NIH microbiologist had received a fat salary since 1995 for doing almost no work.

It is in this context that the National Academies' Institute of Medicine (IOM) has just issued a report on the NIH's organizational structure. The IOM committee came up with a range of solutions to address the agency's various issues. The scientific community, if it wants to see the NIH retain its annual budget of almost $\$ 30$ billion, should work closely with disease advocates and members of Congress to see that some of these measures are implemented.

The IOM grappled with three main problems. The first is an ever-increasing number of institutes with more specialized scientific portfolios. Some who have observed the NIH at close quarters say that consolidating some of the institutes would allow the agency to fund and conduct more coordinated and cutting-edge projects.

However, much of the agency's generous budget increases have resulted from lobby groups pushing for funding for their favourite institutes. Getting rid of the super-specialized structure would be politically challenging, as these lobby groups are well supported in Congress, where any reform measure must pass muster. The IOM rejects any general effort at consolidation as more trouble than it's worth. This isn't particularly brave, although it may well be prudent.

But the IOM report does recommend two specific mergers: between the human genome and general medical-sciences institutes, and between the institutes of alcohol and drug abuse. Both proposals have considerable merit, although it is far from clear whether Congress will ratify even this relatively minor consolidation.

The problems posed by the proliferation of NIH institutes over the years are compounded by the weakness of the director's office. The IOM recommends giving the director more money for crossNIH research projects and for a special-projects programme, initially worth $\$ 100$ million, that would be loosely modelled on the Defense Advanced Research Projects Agency (DARPA), to support high-risk research. These proposals would stimulate work in emerging fields and in areas that cross institute boundaries, as well as giving the director more clout in persuading institutes to cooperate.

Finally, the report tackles the issue of political influence over the NIH's activities. Many of the IOM's recommendations aim to tweak the balance between politicians, scientists and NIH officials. The committee's suggestion that all institute directors be appointed by the NIH director — not by the health secretary — would merely formalize existing practice. Its proposal to reform the external advisory system is laudable, as the current patchwork of arrangements doesn't always expose senior NIH officials to enough viewpoints.

More contentious is the idea that institute directors have their term in office limited to five years, with possible renewal for only five more after review. While meeting concerns that some institutes lack sufficiently dynamic leadership, this might also remove experienced individuals, exposing the institutes to more political interference.

The IOM's ideas are hardly revolutionary: it issued similar findings in 1984, but they were ignored. The scientific community and Congress, which is likely to consider new authorization legislation for the NIH next year, should instigate some intelligent reforms, which could help forestall future management problems at the agency.

\section{Welcome to the Anthropocene}

The sizzling, soaraway summer mustn't get in the way of European climate scientists' objectivity.

$\mathrm{M}$ eteorologists, atmosphere researchers and climate modellers throughout Europe have a summer job this year. Reporters and television crews are queuing up for interviews, demanding explanations about whether the current heatwave means that man-made climate change has finally arrived.

The heat produces strange fancies in some quarters. On 8 August, for example, Germany's best-selling newspaper, the Bild, splashed this on its front page: "Heat researchers alarmed: Equator dramatically shifted." That kind of thing doesn't do much for public understanding of science. But in these overheated days, it is essential that scientists and journalists find the right balance in telling people what they should expect, or even fear, in tomorrow's weather.

Some may be tempted to use the heatwave to ram home the fact that climate change is probably with us, but researchers must not overshoot the mark in their public statements. Unusually warm summers, after all, occur from time to time anyway.

But there's nothing wrong with scientists taking the opportunity to remind the public and policy-makers that climate change is real. Global mean temperatures have increased by about $1^{\circ} \mathrm{C}$ over the past hundred years, and will probably keep rising. Evidence is growing that this trend will lead to changes in atmospheric circulation that correlate with increased occurrence of extreme weather events, such as storms, droughts, floods and heatwaves (see Nature 421, 805;2003).

Humans have had little experience of climate change during our brief, recorded history. Throughout the Holocene - the past 11,000 years or so - global mean temperatures have been pretty stable. But during glacial and inter-glacial times, for example, people had to adapt to substantial climate fluctuations.

As we enter a period that climate researchers have dubbed the 'Anthropocene', we must develop strategies to mitigate the impact of climate change on health, safety and prosperity. Those who can afford it can take out insurance. Perhaps the current heatwave in wealthy Western Europe will build public support for a global fund to help the billions of people in poor countries who don't have that choice. 